\title{
In-situ Investigation of Lead-free Solder Alloy Formation Using a Hot-plate Microscope
}

\author{
Bergmann, René; Tang, Peter Torben; Hansen, Hans Nørgaard; Møller, Per
}

Published in:

Proceedings of the 9th IEEE Electronics Packaging Technology Conference

Link to article, DOI:

10.1109/EPTC.2007.4469822

Publication date:

2007

Document Version

Publisher's PDF, also known as Version of record

Link back to DTU Orbit

Citation $(A P A)$ :

Bergmann, R., Tang, P. T., Hansen, H. N., \& Møller, P. (2007). In-situ Investigation of Lead-free Solder Alloy Formation Using a Hot-plate Microscope. In Proceedings of the 9th IEEE Electronics Packaging Technology Conference IEEE. https://doi.org/10.1109/EPTC.2007.4469822

\section{General rights}

Copyright and moral rights for the publications made accessible in the public portal are retained by the authors and/or other copyright owners and it is a condition of accessing publications that users recognise and abide by the legal requirements associated with these rights.

- Users may download and print one copy of any publication from the public portal for the purpose of private study or research.

- You may not further distribute the material or use it for any profit-making activity or commercial gain

- You may freely distribute the URL identifying the publication in the public portal 


\title{
In-Situ Investigation of Lead-Free Solder Alloy Formation using a Hot-Plate Microscope
}

\author{
René Bergmann ${ }^{1)}$, Peter Torben Tang ${ }^{2)}$, Hans Nørgaard Hansen ${ }^{1)} \&$ Per Møller ${ }^{1)}$ \\ 1) Department of Manufacturing Engineering and Management (IPL), Technical University of Denmark \\ Produktionstorvet, Building 427S, 2800 Kgs. Lyngby, Denmark \\ E-mail: rbe@ipl.dtu.dk \\ 2) IPU - Manufacturing \\ Produktionstorvet, Building 425, 2800 Kgs. Lyngby, Denmark \\ E-mail: $\underline{\mathrm{tt} @ \text {,ipu.dk }}$
}

\begin{abstract}
This work presents the advantages of using a hot-plate microscope for investigation of new (high-temperature) leadfree solders as in-situ analysis tool and preparation equipment. A description of the equipment and the preparation method is given and some examples are outlined. The formation of small AuSn-based, homogeneous and un-oxidized solder spheres will be demonstrated. Moreover the possibility of using this equipment as a sample preparation method to further investigation is shown. As example the equipment was used to produce samples for Vickers microhardness measurement of important phases of the Au-Sn system. The measured values are comparable to those found in the literature. An outlook to further research is also given.
\end{abstract}

\section{Introduction}

Since the European RoHS [1] came into effect in July 2006 the development of (high-temperature) lead-free solder alternatives, especially as first-level solder material [2], became more important. It is still unspecified exactly how long the exceptions, covering the Pb-rich solders [3], will be in force. Therefore an easy and fast method for preparation and investigation of new solder material combinations is needed.

In most experiments from the literature, either investigating solder materials or preparing samples for phase diagram investigations, specimens were prepared by encapsulating portions of metals (powders, granules, shots) into quartz tubes under vacuum and melting them at high temperatures. $[4,5,6,7,8]$ In other cases alumina crucibles and induction/ electron beam melting under argon atmosphere are used to produce samples. $[9,10]$ A vacuum furnace was used by Law et al. [11]. Often mechanical mixing or shaking is necessary to ensure homogeneity. $[5,12,7,8]$

Annealing steps ranging from hours to months are used to create special intermetallic phases within an alloy.

Another method to investigate phase diagrams, the microstructure or diffusion properties of a material combination is the diffusion couple technique. $[13,14,15]$ The specimens produced with this technique are normally not useable for differential scanning calorimetry (DSC)/ differential thermal analysis (DTA) measurements or mechanical tests.

To form solder balls for further experiments, such as shear tests, several techniques are found in the literature. Kim et al. [5] shaped the molten alloy into a wire-type specimen, cut pieces and dropped them into hot silicon oil to form spheres
$(750 \mu \mathrm{m})$. Hot-rolling of an ingot and subsequent punching into disks which were also remelted in silicon oil was used by Lee et al. [12] to make spherical balls $(760 \mu \mathrm{m})$. Cutting small pieces from an ingot and remelting (with flux) them onto an aluminum plate to produce bumps $(760 \mu \mathrm{m})$ was used by Law et al. [11]. In all cases relatively high amount of material is used to produce an ingot for further experiments. This could be very material consuming and expensive especially when $\mathrm{Au}$ or Ag are used in high amounts.

Moreover in the case of experimental material compositions it is not possible to use electroplating to create bumps like in normal production processes [2]. Nearly each new composition needs the development of a dedicated electroplating bath.

As an alternative method the authors will present the benefits of using a hot-plate microscope with optical in-situ investigation (imaging/video system) of the melting and solidification process to examine small solder spheres. As example of using the equipment as a preparation tool, samples with different compositions of $\mathrm{Au}$ and $\mathrm{Sn}$ were produced and Vickers microhardness values of important $\mathrm{Au}-\mathrm{Sn}$ phase determined.

\section{Experimental Setup}

As schematically shown in Fig. 1, the hot-plate microscope equipment consists of three main parts.

\section{1) Vacuum system \\ 2) Specimen chamber with heating system \\ 3) Microscope and imaging system}

The essential part of the equipment is the specimen chamber in which a high-vacuum $\left(<1 \times 10^{-3}\right.$ mbar $)$ can be created, controlled by pressure measurement. Inside this chamber a molybdenum plate $(6 \times 8 \mathrm{~mm})$ is mounted between the electrical contacts of a current heating system. The heating system can reach a temperature up to approximately $1400^{\circ} \mathrm{C}$ and is equipped with water cooling. A specimen holder or crucible, up to $6 \mathrm{~mm}$ in height, can be placed on the molybdenum plate. During heating an optional flow of reducing hydrogen gas can be applied. The chamber is sealed by a removable glass lid for optical in-situ observations. Using an Olympus SZ61 stereo-microscope, a digital camera and analySIS getIT imaging software, it is possible to photograph and film the specimen in-situ. 


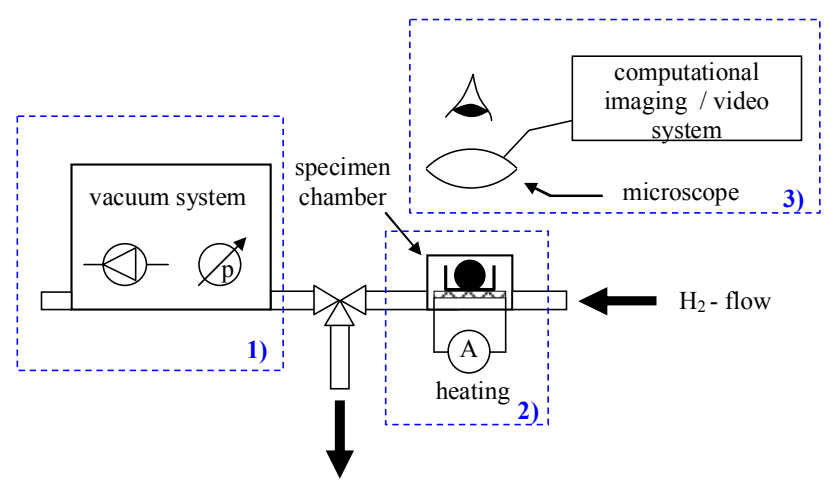

Fig. 1. Experimental setup

\section{Experimental Procedure}

In general metal (solder) spheres with a diameter between $0.5 \mathrm{~mm}$ to $4.0 \mathrm{~mm}$ will be produced and investigated using the hot-plate microscope, Fig. 2.

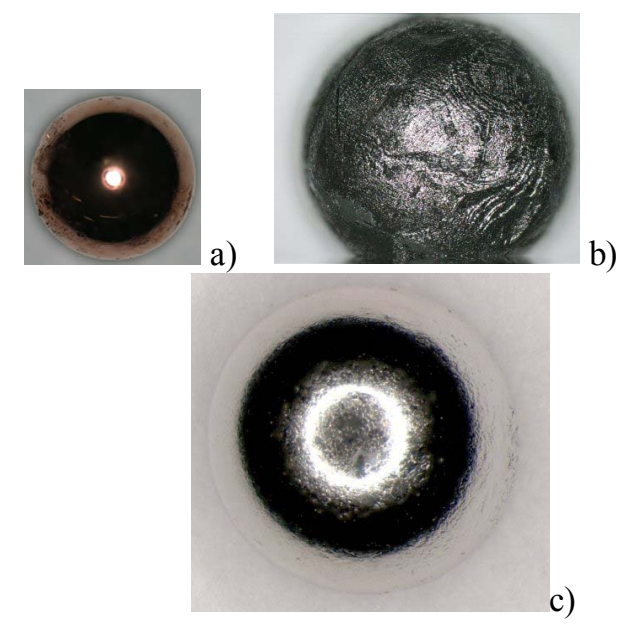

Fig. 2. Examples of metal (solder) spheres; a) $\mathrm{Cu}(1.1 \mathrm{~mm})$ b) $90 \mathrm{~Pb} 10 \mathrm{Sn}(2.1 \mathrm{~mm})$ c) $80 \mathrm{Au} 20 \mathrm{Sn}(\mathrm{Ni})(3.5 \mathrm{~mm})$

The experimental procedure to create such a sphere is divided into three parts:

\section{1) Weighting and pressing \\ 2) Sphere forming \\ 3) Heating and conditioning}

In the first step high purity metal powders (depending on the composition) are carefully weighted (accuracy $0.1 \mathrm{mg}$ ) and mixed inside a specially designed pressing tool (reducing the lose of material during the weighting and pressing step) to form small tablets. If the tablets are too fragile to be moved, polyethylene glycol (PEG) can be used as a binder.

Such a tablet is then melted inside a cylindrical aluminum oxide $\left(\mathrm{Al}_{2} \mathrm{O}_{3}\right)$ crucible $(70 \mu \mathrm{l}$, diameter $6 \mathrm{~mm})$ to form a solder sphere. Figs. 3a-f show this forming process for a eutectic 80Au20Sn (wt.\%) powder mixture with the addition of a small amount of $\mathrm{Ni}$.

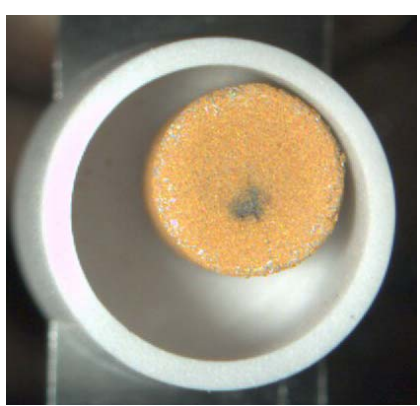

a)

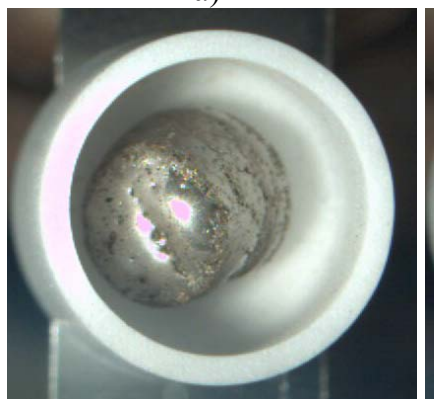

c)

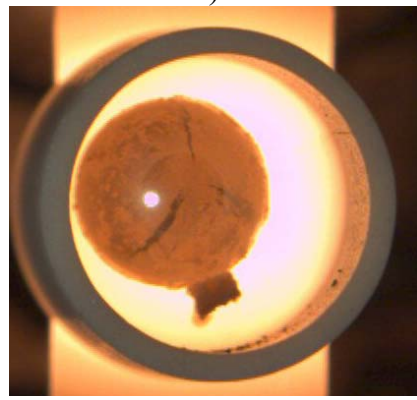

e)

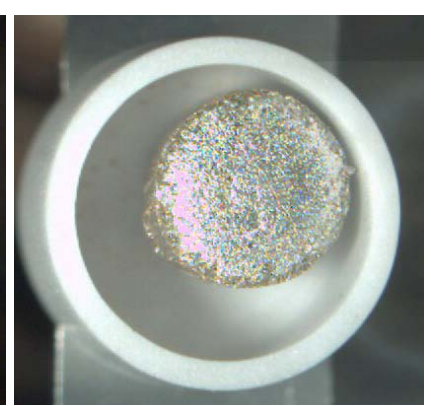

b)

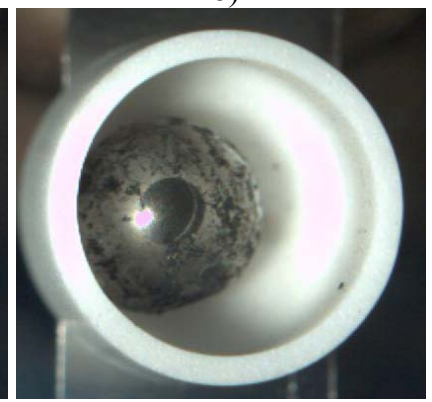

d)

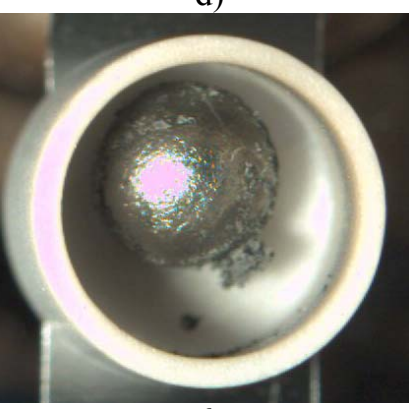

f)
Fig. 3a-f. Forming process (eutectic 80Au20Sn powder mixture with a small amount of $\mathrm{Ni}$ )

It is necessary to use the cylindrical crucible because of the movement of the metal portion during the forming process from tablet to sphere (see Fig. 3c and Fig. 3d). Otherwise the tablet would not stay on the molybdenum plate and would also be soldered to this. The process is done under hydrogen flow to prevent further oxidation of the material and to start the reduction of the oxides on the surface of the developing sphere, cp. Fig. 3e.

As seen in Fig. 3e and Fig. 3f some non-metal impurities came out during the sphere forming process. Therefore it is necessary to take out the metal sphere of the camber and clean it. Normally it is done by washing in ethanol and drying.

After the forming process the solder sphere is placed into the chamber again and remelted in the heating and conditioning step. To prevent the soldering of the sphere to the molybdenum plate and to ensure a good flow of the hydrogen around the sphere, flat $\mathrm{Al}_{2} \mathrm{O}_{3}$ plates $(6 \times 6 \mathrm{~mm})$ are used to carry the specimen. Additionally the first experiments show that it is easier to observe the sphere and to remove the oxides if the sphere is placed on the plate instead of inside the crucible.

Doing so it is possible to in-situ investigate and record the melting and solidification process of a solder sphere using the microscope and the computational imaging and video system. 
Fig. 4 show a melting and solidification sequence of the solder sphere, formed in the previous forming step (Fig. 3).

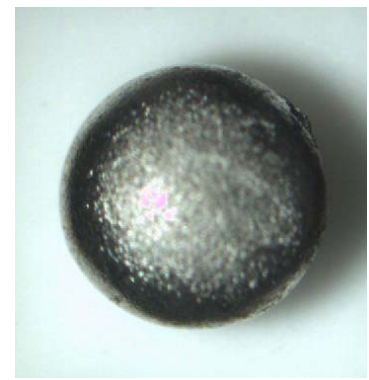

a)

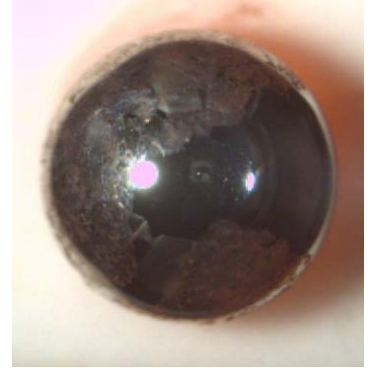

c)

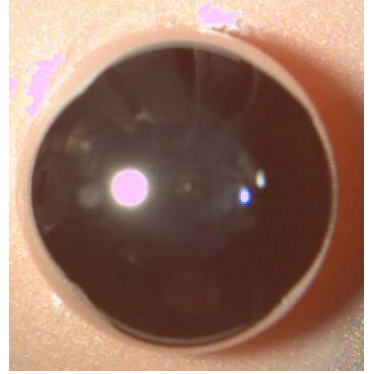

e)

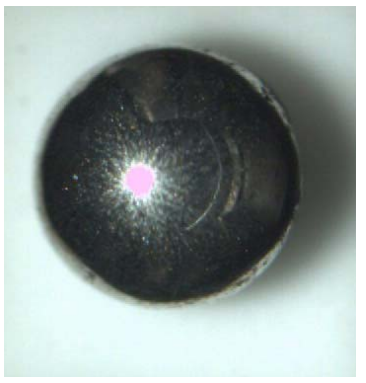

b)

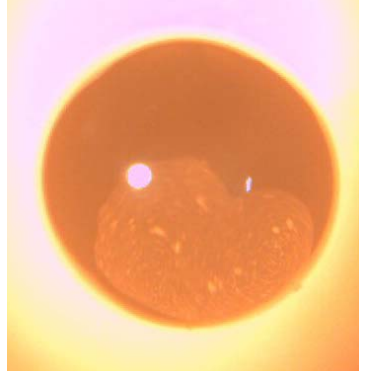

d)

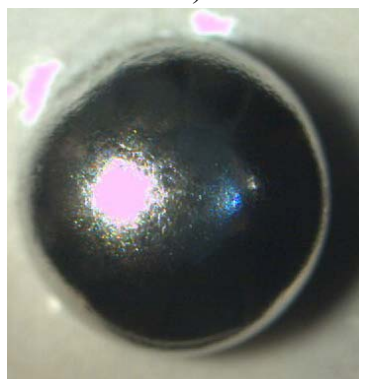

f)
Fig. 4a-f. Heating and conditioning process (eutectic 80Au20Sn powder mixture with a small amount of $\mathrm{Ni}$ )

As see in Figs. 3c-e the remaining oxides are merging on the liquid surface and form a small area during heating. By further heating and holding on high temperature all oxides can be reduced. In addition to the small size of the sphere, the high temperatures ensure a good homogeneity inside the material. A shiny liquid solder sphere, Fig. 3e is created which can be cooled down, Fig. 3f.

The melting and solidification can be conducted slow or fast. Using fast cooling, short processing time (10-15 $\mathrm{min})$ allows for rapid screening of different compositions.

Because of the small size of the samples the spheres can easily be investigated further by scanning electron microscopy (SEM), light optical microscope (LOM), energy dispersive Xray analysis (EDX), X-ray diffraction (XRD) or mechanical tests as shown in the following paragraphs. The weight of a solder sphere is compatible with the amounts used in DTA/DSC analyses.

Additionally the equipment can be used to produce prototype solder balls (diameter app. $500 \mu \mathrm{m}$ ) of new material combinations for shear tests. In this case metal spheres produced with the hot-stage microscope are pressed or rolled (smashed in the case of brittle materials) into thin plates, cut into small pieces and remelted inside the chamber (4-6 pieces at the time) under hydrogen to prevent re-oxidation

\section{Au20Sn solder sphere}

To demonstrate the advantage of the hot plate microscope to create a homogeneous and oxide-free material, $144.4 \mathrm{mg}$ of $\mathrm{Au}$ and $\mathrm{Sn}$ powder - a slightly hypoeutectic composition of 83.1Au16.9 Sn (wt.\%) - was melted and slowly cooled down.

As seen in Fig. 5 and Fig. 6, a very homogeneous and oxide-free alloy was created after a short holding time at the liquid state under hydrogen flow. The liquid condition, the reduction of the oxides and the solidification was observed by in-situ inspection.

SEM and EDX analyses, Fig. 6, compared with the Au-Sn phase diagram, Fig. 7, revealed the presence of $\zeta$ ' phase $\left(\mathrm{Au}_{5} \mathrm{Sn}\right)$ intermetallic precipitates inside an 80Au20Sn matrix. The 80Au20Sn matrix itself consists of a fine mixture (clearly visible in Fig. 6 as light and dark areas) of $\zeta$ ' phase $\left(\mathrm{Au}_{5} \mathrm{Sn}\right)$ and $\delta$ phase (AuSn).

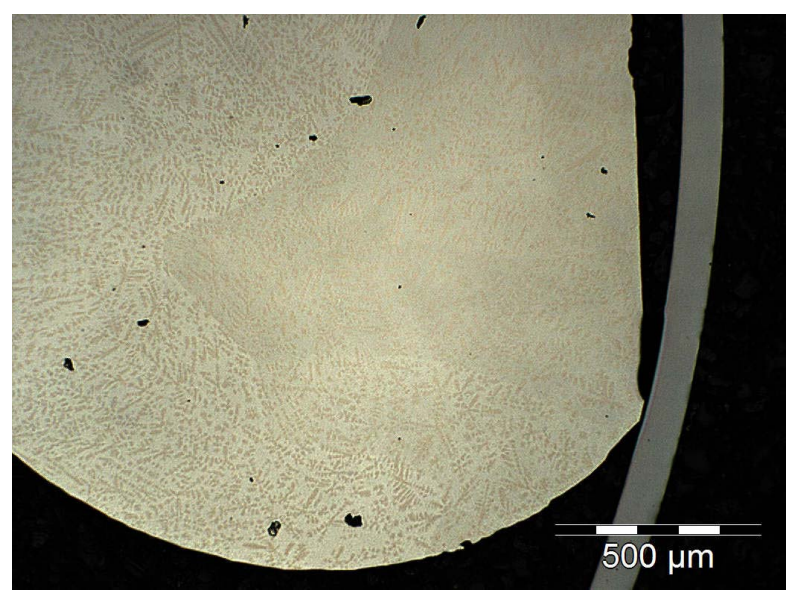

Fig. 5. LOM cross-section; bright eutectic 80Au20Sn matrix with dark '`' phase $\left(\mathrm{Au}_{5} \mathrm{Sn}\right)$ precipitates.

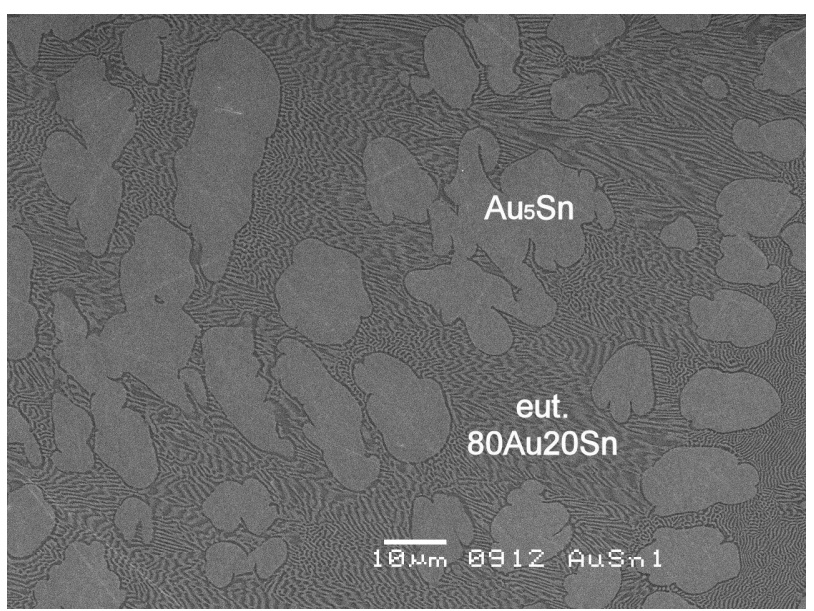

Fig. 6. SEM/EDX cross-section; eutectic 80Au20Sn matrix with light $\zeta$ ' phase $\left(\mathrm{Au}_{5} \mathrm{Sn}\right)$ precipitates. 


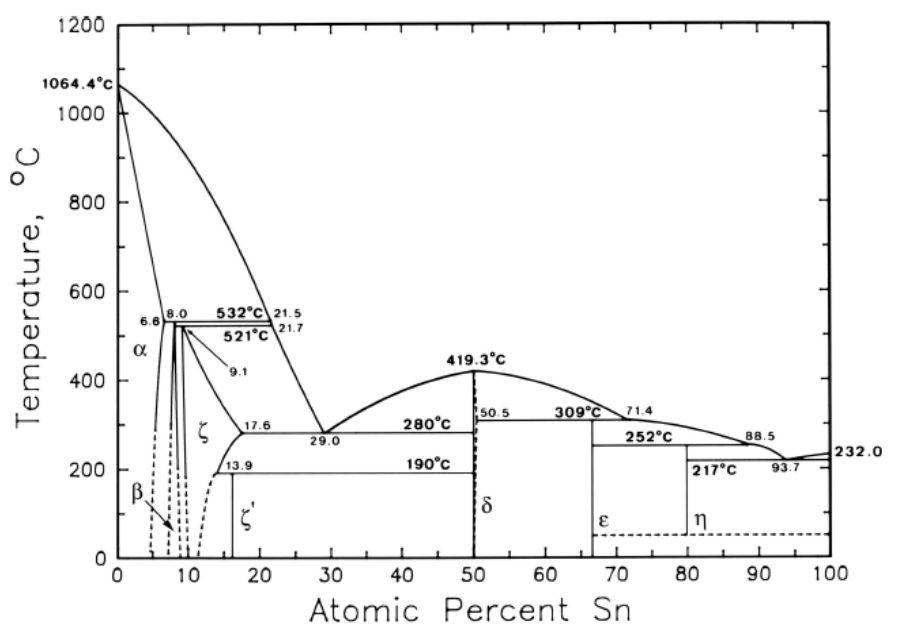

Fig. 7. Au-Sn phase diagram $[9,16,17]$

\section{Hardness Measurement of Au-Sn phases}

To present the possibility of using the hot-stage microscope for sample preparation, several spheres with compositions of $\mathrm{Au}$ and $\mathrm{Sn}$ according to the $\mathrm{Au}-\mathrm{Sn}$ phases $\zeta$, $\zeta$ ' $\left(\mathrm{Au}_{5} \mathrm{Sn}\right), \delta(\mathrm{AuSn}), \varepsilon\left(\mathrm{AuSn}_{2}\right)$ and $\eta\left(\mathrm{AuSn}_{4}\right)$, see $\mathrm{Au}-\mathrm{Sn}$ phase diagram Fig. 7, as well as eutectic 80Au20Sn (wt.\%) samples were produced, following the described experimental procedure. Afterwards the spheres were preparated using standard metallographic preparation methods and SEM/EDX analysis was used to identify the developed phases inside the sphere. The microhardness measurements were carried out using a Vickers microhardness measurement system, FM-700 Future-Tech and JK Lab software.

Depending on the size of the measurable area and the hardness of the phase, loads of $1 \mathrm{~g}$ or $10 \mathrm{~g}$ and a dwell time of $5 \mathrm{~s}$ was used.

The obtained hardness values (average of 10 measurements) for the Au-Sn phases were compared to results from the literature, compiled in Table 1. Chromik et al. [17] presented values measured by Berkovich nanoindenation in solid state aged diffusion couples with a maximum load between 0.7 and $9.5 \mathrm{mN}(0.071 \mathrm{~g}-0.97 \mathrm{~g})$ and Vickers microindentation on bulk $\delta$ (AuSn). As the microhardness values in this work are obtained in $\mathrm{HV}$ a conversion of the Berkovich (based on a projected area) values from Chromik was necessary. This is possible due to the fact that the Vickers and Berkovich indenter geometries have the same projected area versus depth relationship. [17, 18]

Ciulik and Notis [19] measured the hardness of several gold-rich phases by Vickers microindentation with a load of $50 \mathrm{~g}$ on two-phase bulk alloys. Vicenzo et al. [20] obtained values (estimated from a given diagram) by indentation depthload measurements with a peak load of $10 \mathrm{mN}(1,02 \mathrm{~g})$ on electrodeposited thick films and Ghosh et al. [21] measured the hardness of $\mathrm{AuSn}_{4}$ bulk material by microindentation (10$50 \mathrm{~g}$ load).

In general the hardness values for the Au-Sn phases measured in this study fit well to the values obtained either by Ciulik and Notis or by Chromik. The values for $\zeta, \zeta, \varepsilon$ and pure Sn are in agreement with Ciulik and Notis, especially $\varepsilon$. The reason for this might be the similar hardness testing method. In contrast the hardness values for $\delta$ and $\eta$ fit well to the values reported by Chromik. In case of $\delta$ the very good agreement could also originate from similar testing methods, since $\delta$ also was tested by Vickers microindentation. [17]

A well known effect with hardness measurements is the possible dependence of the hardness from the applied load, i.e. indention depth/size. The comparison of the values for the $\delta, \varepsilon$ and $\eta$ phases, obtained in this study, with the numbers from literature $[17,19,21]$ may support this effect for these phases.

Further the authors support the view of Chromik that the high hardness values measured by Vicenzo are due to effects (small grain size) from the electrodeposition process, as none of the measured values fit to our results.

Table 1. Hardness values of Au-Sn phases measured in this work with values from the literature for comparison.

\begin{tabular}{|c|c|c|}
\hline Phase & $\begin{array}{l}\text { Hardness } \\
(\mathrm{HV} \pm \sigma)\end{array}$ & Source \\
\hline $\mathrm{Au}$ & $\begin{array}{l}66 \pm 1.5,10 \mathrm{~g} \\
96 \pm 9 \\
36.5 \pm 0.8\end{array}$ & $\begin{array}{l}\text { this work } \\
{[17]} \\
{[19]}\end{array}$ \\
\hline$\zeta$ & $\begin{array}{l}86 \pm 8,1 \mathrm{~g} \\
100 \pm 4 \\
270 \pm 13\end{array}$ & $\begin{array}{l}\text { this work } \\
{[19]} \\
{[20]}\end{array}$ \\
\hline$\zeta^{\prime}\left(\mathrm{Au}_{5} \mathrm{Sn}\right)$ & $\begin{array}{l}143 \pm 8,10 \mathrm{~g} \\
236 \pm 19 \\
126 \pm 5 \\
178 \pm 16\end{array}$ & $\begin{array}{l}\text { this work }^{\text {a) }} \\
{[17]} \\
{[19]} \\
{[20]}\end{array}$ \\
\hline $\begin{array}{l}\text { Eut. 80Au20Sn } \\
\left(\zeta^{\prime}+\delta\right)\end{array}$ & $\begin{array}{l}177 \pm 7,10 \mathrm{~g} \\
123 \pm 19 \\
133 \\
211 \pm 29\end{array}$ & $\begin{array}{l}\text { this work } \\
{[17]^{\text {b) }}} \\
{[19]^{\text {b) }}} \\
{[20]^{\text {c) }}}\end{array}$ \\
\hline$\delta(\mathrm{AuSn})$ & $\begin{array}{l}107 \pm 1,10 \mathrm{~g} \\
104 \pm 6 \\
146 \pm 4 \\
199 \pm 19\end{array}$ & $\begin{array}{l}\text { this work } \\
{[17]} \\
{[19]} \\
{[20] \text { in }[17]}\end{array}$ \\
\hline$\varepsilon\left(\mathrm{AuSn}_{2}\right)$ & $\begin{array}{l}207 \pm 3,10 g \\
274 \pm 38 \\
206 \pm 4\end{array}$ & $\begin{array}{l}\text { this work } \\
{[17]} \\
{[19]}\end{array}$ \\
\hline$\eta\left(\mathrm{AuSn}_{4}\right)$ & $\begin{array}{l}87 \pm 4,10 g \\
113 \pm 19 \\
60 \pm 6\end{array}$ & $\begin{array}{l}\text { this work } \\
{[17]} \\
{[21] \text { in [17] }}\end{array}$ \\
\hline $\mathrm{Sn}$ & $\begin{array}{l}9 \pm 0.5,10 \mathrm{~g} \\
24 \pm 7 \\
7 \pm 0.5\end{array}$ & $\begin{array}{l}\text { this work } \\
{[17]} \\
{[19]}\end{array}$ \\
\hline
\end{tabular}

\section{Further Investigation}

In additional experiments 80Au20Sn-based alloys with small amounts of $\mathrm{Ni}, \mathrm{Co}, \mathrm{Cu}, \mathrm{Ag}$ and $\mathrm{Pt}$ will be created to 
investigate the influence of these elements on the solder properties. The possibility to rapidly produce solder spheres of new experimental compositions will be used to evaluate the strength of several solder/UBM (Under Bump Metallization) connections and the wetability of the solders.

\section{Conclusions}

A very useful tool for (high-temperature) lead-free solder development and investigation was presented. The usability of the equipment was demonstrated using AuSn-based solders. The possibility of creating - with in-situ observation homogenous, oxide-free solder spheres for succeeding investigations was shown. It can be stated, that the use of the hot-plate microscope to prepare samples for hardness measurement was successful, as obtained hardness values for $\mathrm{Au}-\mathrm{Sn}$ phases from produced metal spheres are comparable to those found in literature.

\section{Acknowledgments}

We acknowledge the Danish Ministry of Science, Technology and Development for financial support through the innovation consortium "MatPack" (project no 07-003145).

The authors furthermore wish to thank Mr. H.C. Dam and Mr. K.Aa. Thorsen for valuable advice and assistance with the hot-stage microscope as well as the Danish Technological Institute for carrying out some of the SEM/EDX analysis.

\section{References}

1. European Union, "Directive 2002/95/EC of the European Parliament and of the Council of 27 January 2003 on the Restriction of the Use of Certain Hazardous Substances in Electrical and Electronic Equipment," OJEU, Vol. L37 (2003), pp. 19-23.

2. Lau, J. H., Low Cost Flip Chip Technologies, McGrawHill (New York, 2000).

3. European Union, "2005/747/EC: Commission Decision of 21 October 2005 amending for the purposes of adapting to technical progress the Annex to Directive 2002/95/EC of the European Parliament and of the Council on the restriction of the use of certain hazardous substances in electrical and electronic equipment," OJEU, Vol. L280 (2005), pp. 18-19.

4. Kim, J.H., Jeong, S.W., Lee H. M., "ThermodynamicAided Alloy Design and Evaluation of Pb-free Solders for High-Temperature Applications," Mater. Trans., Vol. 43, No. 8 (2002), pp. 1873-1878.

5. Kim, S.S., Kim, J.H., Booh, S.W., Kim, T.-G., Lee, H. M., "Microstructural Evolution of Joint Interface between Eutectic 80Au-20Sn Solder and UBM," Mater. Trans., Vol. 46, No. 11 (2005), pp. 2400-2405.

6. Takaku, Y., Ohnuma, I., Kainuma, R., Yamada, Y., Yagi, Y., Nishibe, Y., "Development of Bi-Base HighTemperature Pb-Free Solders with Second-Phase Dispersion: Thermodynamic Calculation, Microstructure, and Interfacial Reaction," J. Electron. Mater., Vol. 35, No. 11 (2006), pp. 1926-1932.

7. Walle, C., Neumann Torgersen, A., Karlsen, O.B., Kjekshus, A., Klewe, B., "The ternary system Au-Cr-Sn and the crystal structure of Au-sub 1.15-Cr-sub 2-Sn-sub
8.85," J. Alloy Comp., Vol. 308, No. 1 (2000), pp. 126133.

8. Offernes, L., Neumann Torgersen, A., Kjekshus, A., "The ternary system Au-Mn-Sn," J. Alloy Comp., Vol. 307, No. 1-2 (2000), pp. 174-178.

9. Ciulik, J., Notis, M. R., "The Au-Sn phase diagram," J. Alloy Comp., Vol. 191, No. 1 (1993), pp. 71-78.

10. Anhöck, S., Oppermann, H., Kallmayer, C., Aschenbrenner, R., Reichel, H., Thomas L., "Investigation of Au-Sn alloys on different end-metallizations," $3 r d$ European Conference on Electronic Packaging Technology (EuPac '98), Nuremberg, Germany, June 1517, 1998.

11. Law, C.M.T., Wu, C.M.L., Yu, D.Q., Li, M., "Interfacial Microstructure and Strength of Lead-Free Sn-Zn-RE BGA Solder Bumps," Trans. Adv. Pack., Vol. 28, No. 2 (2005), pp. 252-258.

12. Lee, J.-H., Park, D.-J., Heo, J.-N., Lee, Y.-H., Shin, D.-H., Kim, Y.-S., "Reflow characteristics of Sn-Ag matrix insitu composite solders," Scr. Mater., Vol. 42, No. 8 (2000), pp. 827-831.

13. Yamada, T., Miura, K., Kajihara, M., Kurokawa, N., Sakamoto, K., "Formation of intermetallic compound layers in $\mathrm{Sn}-\mathrm{Au}-\mathrm{Sn}$ diffusion couple during annealing at 433 K," J. Mater. Sc., Vol. 39, No. 7 (2004), pp. 23272334.

14. Kodentsov, A.A., Bastin, G.F., Loo van, F.J.J., "The diffusion couple technique in phase diagram determination," J. Alloy. Comp., Vol. 320, No. 2 (2001), pp. 207-217.

15. Chang, C.W., Lee, Q.P., Ho, C.E. , Kao, C.R., "CrossInteraction Between $\mathrm{Au}$ and $\mathrm{Cu}$ in $\mathrm{Au}-\mathrm{Sn}-\mathrm{Cu}$ Ternary Diffusion Couples," J. Electron. Mater.,, Vol. 35, No. 2 (2006), pp. 366-371.

16. Okamoto, H., “Au-Sn (gold-tin)," J. Phase Equilib., Vol. 14, No. 6 (1993), pp. 765-766.

17. Chromik, R.R., Wang, D-N., Shugar. A., Limata. L., Notis, M.R., Vinci, R.P., "Mechanical properties of intermetallic compounds in the Au-Sn system," J. Mater. Res., Vol. 20, No. 8 (2005), pp. 2161-2171.

18. Fischer-Cripps, A.C., Nanoindentation, Springer (New York, 2002), pp. 126-141.

19. Ciulik, J., Notis, M.R., "Phase Equilibria and Physical Properties in the Au-Sn System," Proc 2nd ASM International Electronic Materials and Processing Congress, Warrendale, April.1989, pp. 57-61.

20. Vicenzo, A., Rea, M., Vonella, L., Bestetti, M., Cavallotti, P.L., "Electrochemical deposition and structural characterization of Au-Sn alloys," J. Sol. State Electrochem., Vol. 8, No. 3 (2004), pp. 159-166.

21. Ghosh, G., "Elastic properties, hardness, and indentation fracture toughness of intermetallics relevant to electronic packaging," J. Mater. Res., Vol. 19, No. 5 (2004), pp. 1439-1454. 